\title{
Multipotentials of new asymmetric cellulose triacetate membrane for on-line hemodiafiltration both in postdilution and predilution
}

Yusaku Tanaka ${ }^{1 *}$, Hiroyuki Michiwaki ${ }^{1}$, Hirofumi Asa ${ }^{1}$, Daisuke Hirose ${ }^{1}$, Tomohiro Tao $^{1}$ and Jun Minakuchi ${ }^{2}$

\begin{abstract}
Background: On-line hemodiafiltration (OL-HDF) has been generally provided mainly by the postdilution method in Europe and the rest of the world; however, in Japan, it has been provided mostly by the predilution method in order to ameliorate dialysis-related symptoms of dialysis patients by removing larger low molecular weight proteins. This study aimed to elucidate the removal properties of a newly launched asymmetric triacetate (ATA) membrane in OL-HDF both in the postdilution and predilution comparison with other synthetic polymer membranes.

Methods: Six patients treated by OL-HDF at the Kawashima Hospital Group were randomly chosen for each membrane study. The removal properties of low molecular weight proteins were evaluated by $\beta_{2}$-microglobulin $\left(\beta_{2}-M G\right), a_{1}{ }^{-}$ microglobulin $\left(a_{1}-M G\right)$, albumin leakage, selective removal index of $a_{1}-M G$ for albumin, and transmembrane pressure for each treatment group. Two types of ATA membrane were evaluated in the study: FIX-S with mild protein permeability and FIX-U with higher protein permeability in the comparisons with other three types of synthetic polymer membranes.

Results: The removal rate of $\beta_{2}-M G$ showed almost no significant differences between the postdilution and predilution methods in most membrane groups at around $75-80 \%$ without relations to the membrane material and the substitution volume.

The removal rates of $a_{1}-M G$ were markedly different depending on the dilution method of HDF, the membranes, and the substitution volume. Generally, the removal rates of $a_{1}-M G$ were better in the postdilution than the predilution but the selective removals of $a_{1}-M G$ were better in the predilution. The high volume OL-HDF had the risk of excessive albumin leakage in a certain membrane choice.

In the FIX series, the removal rates of $a_{1}-M G$ were sufficient both in the postdilution and predilution with the increase of the substitution volume with suppressing the albumin leakage during the dialysis session. Especially, FIX-U showed higher removal of $\mathrm{a}_{1}-\mathrm{MG}$ with suppressing the albumin leakage.
\end{abstract}

Conclusions: The newly launched ATA membrane could remove $a_{1}-M G$, selectively suppressing the excessive albumin leakage and increasing the substitution volume safely even in high-volume postdilution.

Trial registration: Trial registration: University hospital Medical Information Network (UMIN), UMIN 000035705. Registered 28 January 2019 - Retrospectively registered, https://www.umin.ac.jp/ctr/index-j.htm.

Keywords: On-line hemodiafiltration, Asymmetric cellulose triacetate, $\beta_{2}$-microglobulin, $a_{1}$-microglobulin, Albumin leakage

\footnotetext{
* Correspondence: yu-tanaka0724@khg.or.jp

${ }^{1}$ Clinical Engineering Department, Social Medicine Corporation Kawashima

Association, Kawashima Hospital, 1-1-39, Kitasako, Tokushima City, Tokushima

Prefecture 770-0011, Japan

Full list of author information is available at the end of the article
}

(c) The Author(s). 2019 Open Access This article is distributed under the terms of the Creative Commons Attribution 4.0 International License (http://creativecommons.org/licenses/by/4.0/), which permits unrestricted use, distribution, and reproduction in any medium, provided you give appropriate credit to the original author(s) and the source, provide a link to the Creative Commons license, and indicate if changes were made. The Creative Commons Public Domain Dedication waiver (http://creativecommons.org/publicdomain/zero/1.0/) applies to the data made available in this article, unless otherwise stated. 


\section{Introduction}

On-line hemodiafiltration (OL-HDF) has been generally provided in the postdilution method in Europe and the rest of the world; however, it is quite different in Japan, where most of OL-HDF have been performed in the predilution method. The CONTRAST Study and ESHOL Study reported a better survival of patients in a high-volume substitution group using the postdilution method compared with that in a low-volume substitution group and low-flux HD group [1-3]. However, the membranes used in these reports had smaller pore size and lower permeability than the membranes widely used in Japan. Furthermore, the relationship between substitution volume and solute removal property has not been considered in the studies, which could explain the mechanism of survival advantages of high-volume postdilution OL-HDF.

On the other hand, for OL-HDF in Japan, the predilution method accounted for $95.6 \%$ of all OL-HDF therapies at the end of 2016 [4]. In Japan, the average blood flow rate by predilution and postdilution is $228.7 \mathrm{~mL} / \mathrm{min}$ and 224.9 $\mathrm{mL} / \mathrm{min}$, respectively, which was lower than that in Europe and the world [4]. The predilution method can freely increase the substitution volume even with a low blood flow rate and is able to improve the solute removal efficiency of low molecular weight proteins (LMWPs). Furthermore, if we use a large pore size filter in the predilution method, we can remove larger LMWPs without explosive albumin leakage [5]. The Japanese pioneer doctors found that dialysis prescriptions with larger LMWP removal incurring a certain level of albumin loss have improved various uremic symptoms. Based on these experiences, "protein permeable dialysis" has developed in Japan $[5,6]$.

To increase the removal of LMWPs both in the postdilution and predilution HDF, we have to increase the substitution volume as safely as we can. The newly developed FIX series (NIPRO) is the first membrane for HDF composed of cellulose triacetate (CTA). The current CTA membrane has a symmetric structure, and it has not generally indicated for HDF because of its vulnerability against the high transmembrane pressure
(TMP). The new CTA membrane has an asymmetric structure (asymmetric triacetate ( ATA)) with similar stiffness to other synthetic polymer membranes such as polysulfone, with a smooth inner surface by nanotechnology. Owing to its ability to suppress excessive albumin leakage by reducing fouling through protein adhesion inhibition and avoiding the rise in the TMP, these membranes are expected to have different removal properties from other synthetic polymer membranes. This study aimed to elucidate the removal properties of the ATA membrane in OL-HDF compared to those of synthetic polymer membranes as well as examine the influence of the dilution method and substitution volume on the solute removal.

\section{Subjects and methods}

Six maintenance dialysis patients treated by OL-HDF at Kawashima Hospital Group were randomly selected for each study protocol with each membrane (Table 2). The patient selection criteria required patients to be 20 years or older, but did not concern gender, inpatient/outpatient classification, medical history, or the presence of complications for the patient. We excluded patients with significant inflammatory symptoms and severe impairment of the liver, heart, lungs, etc. This study was reviewed by the Kawashima Hospital Ethics Committee (Approval No.: 0199) and was implemented based on the spirit of the Declaration of Helsinki and in compliance with the ethical guidelines. We obtained written consent from all patients.

We used five types of membranes for OL-HDF, namely TDF20-PV (TDF: Toray Medical Co., Ltd.), GDF-21 (GDF: Nikkiso Co., Ltd.), MFX-25U eco (MFX: NIPRO), FIX-250S eco (FIX-S: NIPRO), and FIX-250U eco (FIX-U: NIPRO). The characteristics of each membrane are shown in Table 1 . The treatment conditions were set: $4 \mathrm{~h}, 3$ times a week, blood flow rate $(\mathrm{QB})=280 \mathrm{~mL} / \mathrm{min}$, and total dialysis fluid flow rate $(\mathrm{QD})=500 \mathrm{~mL} / \mathrm{min}$, with substitution flow rate (QS) kept constant at 250 and $350 \mathrm{~mL} / \mathrm{min}(60$ and $84 \mathrm{~L} / 4 \mathrm{~h}$ ) for predilution and 50

Table 1 Filters' performance

\begin{tabular}{|c|c|c|c|c|c|}
\hline & TDF-20PV & GDF-21 & MFX-25 U eco & FIX-250S eco & FIX-250 U eco \\
\hline Membrane material & PS & PEPA & PES & CTA & CTA \\
\hline Membrane bore $(\mu \mathrm{m})$ & 210 & 210 & 200 & 200 & 200 \\
\hline Membrane thickness ( $\mu \mathrm{m})$ & 40 & 30 & 40 & 25 & 25 \\
\hline Effective membrane area $\left(\mathrm{m}^{2}\right)$ & 2.0 & 2.1 & 2.5 & 2.5 & 2.5 \\
\hline UFR (mL/mmHg/hr) & 72.2 & 64 & 91 & 90 & 99 \\
\hline \multicolumn{6}{|l|}{ SC } \\
\hline Alb & $0.029 \geqq$ & 0.03 & 0.01 & 0.01 & 0.02 \\
\hline$\beta_{2}-M G$ & 0.90 & 0.87 & 0.91 & 0.93 & 1.05 \\
\hline
\end{tabular}

PS Polysulfone, PES Polyethersulfone, UFR Ultrafiltration coefficient, Alb Albumin, PEPA Polyester polymer alloy, CTA Cellulose triacetate, SC Sieving coefficient, $\beta_{2}-M G \beta_{2}$-microglobulin 
and $66 \mathrm{~mL} / \mathrm{min}$ (12 and $16 \mathrm{~L} / 4 \mathrm{~h})$ for postdilution. However, in each dialysis session with GDF, QS was decreased at 250 and $300 \mathrm{~mL} / \mathrm{min}(60$ and $72 \mathrm{~L} / 4 \mathrm{~h})$ for predilution and 42 and $50 \mathrm{~mL} / \mathrm{min}(10$ and $12 \mathrm{~L} / 4 \mathrm{~h}$ ) for postdilution for avoiding the excessive albumin leakage during the session with GDF. The contents of the dialysis fluid were $\mathrm{Na}, 140 \mathrm{mEq} / \mathrm{L} ; \mathrm{K}, 2.0 \mathrm{mEq} / \mathrm{L} ; \mathrm{Ca}, 2.75-3.0$ $\mathrm{mEq} / \mathrm{L} ; \mathrm{Mg}, 1.0 \mathrm{mEq} / \mathrm{L} ; \mathrm{Cl}, 112-113 \mathrm{mEq} / \mathrm{L} ;$ acetate, 8.0 and $10.2 \mathrm{mEq} / \mathrm{L}$; bicarbonate, $25-27.5 \mathrm{mEq} / \mathrm{L}$; and glucose, 100 and $125 \mathrm{mg} / \mathrm{dL}$.

The evaluation items were the removal rate (RR) of $\beta_{2}$-microglobulin ( $\beta_{2}-\mathrm{MG}$ ) and the RR of $\alpha_{1}$-microglobulin $\left(\alpha_{1}-M G\right)$, the removed $\beta_{2}-M G$ quantity and $\alpha_{1}-M G$, the albumin leakage quantity, the selective removal index of $\alpha_{1}$-MG (SRIA), and TMP for each treatment group. The SRIA was calculated as the removed $\alpha_{1}$-MG quantity divided by the albumin leakage quantity in a single session shown in the formula below (Formula 1).

$$
\begin{aligned}
& \text { Selective removal index of } \alpha_{1}-\text { MG (SRIA) } \\
& \quad=\alpha_{1}-\text { MG removal quantity }
\end{aligned}
$$

We also evaluated the relationship between the removed $\alpha_{1}$-MG quantity and the albumin leakage quantity. The RR was measured by taking blood samples at the start of dialysis and $4 \mathrm{~h}$ after, and then corrected by the hematocrit value as shown in the formula below (Formula 2).

$$
\begin{aligned}
& \text { Removal Rate (RR) } \\
& =\left[1-\left\{\mathrm{Ht}_{\text {Pre }} / \mathrm{Ht}_{\text {post }}\right\} \times\left\{\left(1-\mathrm{Ht}_{\text {post }} / 100\right) /\left(1-\mathrm{Ht}_{\text {pre }} / 100\right)\right\} \times\left\{\mathrm{CBI}_{\text {Post }} / \mathrm{CBI}_{\text {Pre }}\right\}\right] \\
& \quad \times 100
\end{aligned}
$$

CBI pre, CBI post Solute concentration before and after dialysis

$\mathrm{Ht}_{\text {pre, }} \mathrm{Ht}$ post Hematocrit before and after dialysis (\%)
The removed quantity of each solute and albumin leakage was evaluated using the partial storage method of the spent dialysate. In the partial storage method, the drained dialysate was extracted at a rate of $0.9 \mathrm{~L} / \mathrm{h}$ using a multi-roller pump (MF-01: manufactured by JMS) and was then stored for $4 \mathrm{~h}$. At our hospital, we recognize that there is no significant difference between the measurement errors of total storage method and partial storage method.

We calculated the mean and standard deviation of the RR of $\beta_{2}$-MG, $\beta_{2}$-MG removal quantity, the RR of $\alpha_{1}$-MG, the $\alpha_{1}$-MG removal quantity, the albumin leakage quantity, the SRIA, and the TMP for each treatment group. Comparisons of the substitution volume for each dilution method were made with the corresponding $t$ test and the Wilcoxon signed rank sum test. Spearman's rank correlation coefficient was used to examine the correlation. All statistical analyses were performed using SPSS statistics ver.23 (IBM), with a significance level of $5 \%$.

\section{Results}

\section{Patients' demographics}

There were no differences among the patients' background characteristics (Table 2).

\section{$\beta_{2}$-MG removal}

The RR of $\beta_{2}$-MG showed almost no significant differences between the postdilution and predilution methods at around $75-80 \%$ without relations to the membrane material and the substitution volume. However, the TDF group showed a slight increase in postdilution by the increase of substitution volume as $78.8 \pm 5.1 \%$ for $12 \mathrm{~L}$ and

\begin{tabular}{|c|c|c|c|c|c|c|}
\hline & TDF-20PV & GDF-21 & $\begin{array}{l}\text { MFX-25 } \\
\text { U eco }\end{array}$ & FIX-250S eco & $\begin{array}{l}\text { FIX-250 } \\
\text { U eco }\end{array}$ & $P$ \\
\hline Patients, N & 6 & 6 & 6 & 6 & 6 & \\
\hline Age (-years-old) & $69.2 \pm 5.4$ & $64.3 \pm 5.5$ & $59.4 \pm 8.6$ & $67.3 \pm 9.3$ & $67 \pm 11.8$ & 0.331 \\
\hline HD dur (years) & $7.9 \pm 6.3$ & $13.3 \pm 9.2$ & 9.5. \pm 9.4 & $9 \pm 11.1$ & $12.5 \pm 6.5$ & 0.693 \\
\hline DW (Kg) & $58 \pm 11.2$ & $65.3 \pm 12$ & $61.1 \pm 5.3$ & $59.2 \pm 6$ & $63.7 \pm 5.1$ & 0.500 \\
\hline $\operatorname{WBC}\left(10^{3} / \mu \mathrm{L}\right)$ & $5.6 \pm 1.1$ & $5.5 \pm 1.4$ & $5.9 \pm 1.8$ & $5.9 \pm 1.7$ & $6.8 \pm 2.5$ & 0.758 \\
\hline $\operatorname{RBC}\left(10^{6} \mu \mathrm{L}\right)$ & $3.5 \pm 0.4$ & $3.5 \pm 0.5$ & $3.3 \pm 0.2$ & $3.6 \pm 0.2$ & $3.6 \pm 0.4$ & 0.666 \\
\hline Hct (\%) & $34 \pm 4$ & $32 \pm 3$ & $32 \pm 2$ & $35 \pm 1$ & $33 \pm 4$ & 0.315 \\
\hline HGB (g/dL) & $11.2 \pm 0.9$ & $11 \pm 1.2$ & $10.4 \pm 0.8$ & $11.6 \pm 0.2$ & $10.5 \pm 1.8$ & 0.392 \\
\hline $\operatorname{PLT}\left(10^{3} / \mu \mathrm{L}\right)$ & $179 \pm 59$ & $197 \pm 14$ & $171 \pm 42$ & $185 \pm 63$ & $218 \pm 59$ & 0.597 \\
\hline $\mathrm{TP}(\mathrm{g} / \mathrm{dL})$ & $6.1 \pm 0.4$ & $6.1 \pm 0.3$ & $6.2 \pm 0.2$ & $6.6 \pm 0.3$ & $6.2 \pm 0.4$ & 0.165 \\
\hline Alb (g/dL) & $3.4 \pm 0.3$ & $3.3 \pm 0.2$ & $3.2 \pm 0.3$ & $3.6 \pm 0.2$ & $3.3 \pm 0.4$ & 0.278 \\
\hline
\end{tabular}
$79.8 \pm 5.1 \%$ for $16 \mathrm{~L}(p=0.028)$. There were no significant differences in the removed $\beta_{2}$-MG quantity per session between the postdilution and predilution methods, while

Table 2 Demographic characters of subjects 
the GDF group showed a significant decrease in the predilution method, with $181.3 \pm 17.2 \mathrm{mg}$ for $60 \mathrm{~L}$ and $137.3 \pm$ $40.8 \mathrm{mg}$ for $72 \mathrm{~L}(p=0.035)$ (Table 3$)$.

\section{$a_{1}-M G$ removal and albumin leakage TDF group}

In the postdilution method, the RR of $\alpha_{1}$-MG was $39.9 \pm$ 9.1\% and $43.8 \pm 7.1 \%$ for $12 \mathrm{~L}$ and $16 \mathrm{~L}$, which indicated a significant increase $(p=0.027)$. The removed $\alpha_{1}-\mathrm{MG}$ quantity was $145.5 \pm 34.4 \mathrm{mg}$ and $154.8 \pm 24.8 \mathrm{mg}$ for $12 \mathrm{~L}$ and $16 \mathrm{~L}$. The albumin leakage was $3.5 \pm 0.3 \mathrm{~g}$ and $4.7 \pm 0.7 \mathrm{~g}$ for $12 \mathrm{~L}$ and $16 \mathrm{~L}$, which indicated a significant increase $(p=$ $0.007)$. The SRIA was $41.1 \pm 7.6$ and $34.1 \pm 7.9$ for $12 \mathrm{~L}$ and $16 \mathrm{~L}$, which indicated a significant decrease $(p=0.01)$.

In the predilution method, the RR of $\alpha_{1}$-MG was 38.6 $\pm 8.9 \%$ and $43.4 \pm 11 \%$ for $60 \mathrm{~L}$ and $84 \mathrm{~L}$. The removed $\alpha_{1}$-MG quantity was $132.4 \pm 22 \mathrm{mg}$ and $165 \pm 50.3 \mathrm{mg}$ for $60 \mathrm{~L}$ and $84 \mathrm{~L}$. The albumin leakage was $3.2 \pm 0.4 \mathrm{~g}$ and $5.3 \pm 0.8 \mathrm{~g}$ for $60 \mathrm{~L}$ and $84 \mathrm{~L}$, which indicated a significant increase $(p=0.002)$. The SRIA was $42.7 \pm 10.9$ and $31.1 \pm 7.4$ for $60 \mathrm{~L}$ and $84 \mathrm{~L}$, which indicated a significant decrease $(p=0.005)$ (Tables 4 and 5).

\section{GDF group}

In the postdilution method, the RR of $\alpha_{1}$-MG was 44.9 $\pm 6.5 \%$ and $50.6 \pm 5.4 \%$ for $10 \mathrm{~L}$ and $12 \mathrm{~L}$, which indicated a significant increase $(p=0.001)$. The removed $\alpha_{1}$-MG quantity was $213.1 \pm 62.6 \mathrm{mg}$ and $255.9 \pm 58.2 \mathrm{mg}$ for $10 \mathrm{~L}$ and $12 \mathrm{~L}$. The albumin leakage was $7.9 \pm 4.5 \mathrm{~g}$ and $16.5 \pm 8.8 \mathrm{~g}$ for $10 \mathrm{~L}$ and $12 \mathrm{~L}$, which indicated a significant increase $(p=0.028)$. The SRIA was $33.7 \pm 16.3$ and $18.2 \pm 6.9$ for $10 \mathrm{~L}$ and $12 \mathrm{~L}$, which tended to decrease.
In the predilution method, the RR of $\alpha_{1}$-MG was 46.1 $\pm 8.9 \%$ and $44.7 \pm 9 \%$ for $60 \mathrm{~L}$ and $72 \mathrm{~L}$. The removed $\alpha_{1}$-MG quantity was $226.1 \pm 49.4 \mathrm{mg}$ and $201.2 \pm 40.1 \mathrm{mg}$ for $60 \mathrm{~L}$ and $72 \mathrm{~L}$, which indicated a significant decrease $(p=0.022)$. The albumin leakage was $11.5 \pm 4.3 \mathrm{~g}$ and $11.5 \pm 5.9 \mathrm{~g}$ for $60 \mathrm{~L}$ and $72 \mathrm{~L}$. The SRIA was $22 \pm 8.2$ and $21.7 \pm 10.7$ for $60 \mathrm{~L}$ and $72 \mathrm{~L}$ (Tables 4 and 5).

\section{MFX group}

In the postdilution method, the RR of $\alpha_{1}$-MG was 46.1 $\pm 10 \%$ and $54 \pm 9.8 \%$ for $12 \mathrm{~L}$ and $16 \mathrm{~L}$, which indicated a significant increase $(p=0.001)$. The removed $\alpha_{1}$-MG quantity was $215.4 \pm 40.7 \mathrm{mg}$ and $244 \pm 40.1 \mathrm{mg}$ for 12 $\mathrm{L}$ and $16 \mathrm{~L}$, which indicated a significant increase $(p=0.02)$. The albumin leakage was $8.1 \pm 1.9 \mathrm{~g}$ and $13.2 \pm 3.9 \mathrm{~g}$ for $12 \mathrm{~L}$ and $16 \mathrm{~L}$, which indicated a significant increase $(p=0.008)$. The SRIA was $28.3 \pm 10.7$ and $20.1 \pm$ 8 for $12 \mathrm{~L}$ and $16 \mathrm{~L}$, which indicated a significant decrease $(p=0.005)$.

In the predilution method, the RR of $\alpha_{1}$-MG was 37.2 $\pm 11 \%$ and $40.7 \pm 11.9 \%$ for $60 \mathrm{~L}$ and $84 \mathrm{~L}$. The removed $\alpha_{1}$-MG quantity was $164.6 \pm 37.2 \mathrm{mg}$ and $185 \pm 34.7 \mathrm{mg}$ for $60 \mathrm{~L}$ and $84 \mathrm{~L}$. The albumin leakage was $4.3 \pm 0.6 \mathrm{~g}$ and $5.6 \pm 1.3 \mathrm{~g}$ for $60 \mathrm{~L}$ and $84 \mathrm{~L}$. The SRIA was $38 \pm 7.3$ and $34.3 \pm 9.3$ for $60 \mathrm{~L}$ and $84 \mathrm{~L}$ (Tables 4 and 5).

\section{FIX-S group}

In the postdilution method, the RR of $\alpha_{1}$-MG was 33.6 $\pm 9.3 \%$ and $34.6 \pm 6.5 \%$ for $12 \mathrm{~L}$ and $16 \mathrm{~L}$. The removed $\alpha_{1}$-MG quantity was $155.3 \pm 30 \mathrm{mg}$ and $153.6 \pm 30.6 \mathrm{mg}$ for $12 \mathrm{~L}$ and $16 \mathrm{~L}$. The albumin leakage was $6.4 \pm 1.5 \mathrm{~g}$ and $6.6 \pm 1.8 \mathrm{~g}$ for $12 \mathrm{~L}$ and $16 \mathrm{~L}$. The SRIA was $25.3 \pm$ 6.6 and $24 \pm 5.7$ for $12 \mathrm{~L}$ and $16 \mathrm{~L}$.

Table 3 Removal rate and removed $\beta_{2}-M G$ quantity

\begin{tabular}{|c|c|c|c|c|c|c|c|}
\hline \multirow{2}{*}{$\begin{array}{l}\text { Substitution } \\
\text { volume (L/session) }\end{array}$} & \multicolumn{3}{|l|}{ Predilution } & \multicolumn{3}{|l|}{ Postdilution } & \multirow[t]{2}{*}{$p$ (4 groups) } \\
\hline & 60 & $84(72)$ & $p$ & $12(10)$ & $16(12)$ & $p$ & \\
\hline \multicolumn{8}{|l|}{ RR (\%) } \\
\hline TDF-20PV & $78.5 \pm 5.4$ & $78.5 \pm 6.8$ & 0.937 & $78.8 \pm 5.1$ & $79.8 \pm 5.1^{*}$ & 0.028 & 0.974 \\
\hline GDF-21 & $77 \pm 9.9$ & $74.3 \pm 11.6$ & 0.117 & $78.3 \pm 2.9$ & $78.4 \pm 5.4$ & 0.897 & 0.886 \\
\hline MFX-25U eco & $81.7 \pm 2.4$ & $82.8 \pm 2$ & 0.219 & $81.5 \pm 2.7$ & $83 \pm 2.4$ & 0.145 & 0.625 \\
\hline FIX-250S eco & $80.5 \pm 2.2$ & $80.9 \pm 3.3$ & 0.587 & $81 \pm 2.4$ & $81.6 \pm 3.5$ & 0.538 & 0.927 \\
\hline FIX-250U eco & $80.2 \pm 3.7$ & $80.5 \pm 3.9$ & 0.672 & $80.8 \pm 4.1$ & $81.7 \pm 3.6$ & 0.233 & 0.902 \\
\hline \multicolumn{8}{|l|}{$\mathrm{RA}(\mathrm{mg})$} \\
\hline TDF-20PV & $156.6 \pm 29.8$ & $168.1 \pm 46.5$ & 0.206 & $165.8 \pm 37.7$ & $161.6 \pm 33.8$ & 0.661 & 0.954 \\
\hline GDF-21 & $181.3 \pm 17.2$ & $137.3 \pm 40.8^{*}$ & 0.035 & $154.8 \pm 53.4$ & $178.2 \pm 25.7$ & 0.236 & 0.163 \\
\hline MFX-25U eco & $212.3 \pm 29$ & $251.2 \pm 99.1$ & 0.321 & $220.4 \pm 42.6$ & \pm 36.4 & 0.081 & 0.564 \\
\hline FIX-250S eco & $167.2 \pm 18.7$ & $168.8 \pm 26.3$ & 0.731 & $169 \pm 24.2$ & $180.6 \pm 28.7$ & 0.303 & 0.772 \\
\hline FIX-250U eco & $226.2 \pm 53.1$ & $274.1 \pm 89.4$ & 0.053 & $219.1 \pm 21.9$ & $226.5 \pm 24.2$ & 0.319 & 0.304 \\
\hline
\end{tabular}

Comparisons between $60 \mathrm{~L}$ and $84 \mathrm{~L}(72 \mathrm{~L})$ in the predilution and between $12 \mathrm{~L}(10 \mathrm{~L})$ and $16 \mathrm{~L}(12 \mathrm{~L})$ in the postdilution were analyzed by the corresponding $t$ test. ${ }^{*} P<0.05$. And comparison among four treatment conditions for each membrane was analyzed by one-way ANOVA 
Table 4 Removal rate and removed $a_{1}-M G$ quantity

\begin{tabular}{|c|c|c|c|c|c|c|c|}
\hline \multirow{2}{*}{$\begin{array}{l}\text { Substitution } \\
\text { volume } \\
\text { (L/session) }\end{array}$} & \multicolumn{3}{|l|}{ Predilution } & \multicolumn{3}{|l|}{ Postdilution } & \multirow{2}{*}{$\begin{array}{l}p \\
\text { (4 groups }\end{array}$} \\
\hline & 60 & $84(72)$ & $p$ & $12(10)$ & $16(12)$ & $p$ & \\
\hline \multicolumn{8}{|l|}{ RR (\%) } \\
\hline TDF-20PV & $38.6 \pm 8.9$ & $43.4 \pm 11$ & 0.083 & $39.9 \pm 9.1$ & $43.8 \pm 7.1^{*}$ & 0.027 & 0.703 \\
\hline GDF-21 & $46.1 \pm 8.9$ & $44.7 \pm 9$ & 0.226 & $44.9 \pm 6.5$ & $50.6 \pm 5.4^{*}$ & 0.001 & 0.518 \\
\hline MFX-25U eco & $37.2 \pm 11$ & $40.7 \pm 11.9$ & 0.155 & $46.1 \pm 10$ & $54 \pm 9.8^{*}$ & 0.001 & 0.065 \\
\hline FIX-250S eco & $29.2 \pm 6.9$ & $27.1 \pm 7.4$ & 0.111 & $33.6 \pm 9.3$ & $34.6 \pm 6.5$ & 0.673 & 0.299 \\
\hline FIX-250U eco & $45.3 \pm 6.1$ & $46.7 \pm 5.2$ & 0.303 & $52.4 \pm 4.4$ & $54.5 \pm 4.9^{*}$ & 0.012 & $60-16 L$ \\
\hline \multicolumn{8}{|l|}{ RA (mg) } \\
\hline TDF-20PV & $132.4 \pm 22$ & $165 \pm 50.3$ & 0.061 & $145.5 \pm 34.4$ & $154.8 \pm 24.8$ & 0.184 & 0.432 \\
\hline GDF-21 & $226.1 \pm 49.4$ & $201.2 \pm 40.1^{*}$ & 0.022 & $213.1 \pm 62.6$ & $255.9 \pm 58.2$ & 0.095 & 0.347 \\
\hline MFX-25U eco & $164.6 \pm 37.2$ & $185 \pm 34.7$ & 0.056 & $215.4 \pm 40.7$ & $244 \pm 40.1^{*}$ & 0.02 & $60-16 \mathrm{~L}$ \\
\hline FIX-250S eco & $131.1 \pm 31.8$ & $126.3 \pm 37$ & 0.415 & $155.3 \pm 30$ & $153.6 \pm 30.6$ & 0.805 & 0.309 \\
\hline FIX-250U eco & $224 \pm 77.1$ & $231.5 \pm 62.4$ & 0.415 & $238.1 \pm 43.8$ & $254.9 \pm 52.6^{*}$ & 0.036 & 0.835 \\
\hline
\end{tabular}

Comparisons between $60 \mathrm{~L}$ and $84 \mathrm{~L}(72 \mathrm{~L})$ in the predilution and between $12 \mathrm{~L}(10 \mathrm{~L})$ and $16 \mathrm{~L}(12 \mathrm{~L})$ in the postdilution were analyzed by the corresponding $t$ test. ${ }^{*} P<0.05$. And comparison among four treatment conditions for each membrane was analyzed by one-way ANOVA and Tukey-Kramer test

$R R$ Removal rate, $R A$ Removal amount

In the predilution method, the RR of $\alpha_{1}$-MG was 29.2 $\pm 6.9 \%$ and $27.1 \pm 7.4 \%$ for $60 \mathrm{~L}$ and $84 \mathrm{~L}$. The removed $\alpha_{1}$-MG quantity was $131.1 \pm 31.8 \mathrm{mg}$ and $126.3 \pm 37 \mathrm{mg}$ for $60 \mathrm{~L}$ and $84 \mathrm{~L}$. The albumin leakage was $4.1 \pm 0.4 \mathrm{~g}$ and $3.7 \pm 0.5 \mathrm{~g}$ for $60 \mathrm{~L}$ and $84 \mathrm{~L}$. The SRIA was $31.8 \pm$ 7.1 and $34 \pm 9.1$ for $60 \mathrm{~L}$ and $84 \mathrm{~L}$ (Tables 4 and 5).

\section{FIX-U group}

In the postdilution method, the RR of $\alpha_{1}$-MG was 52.4 $\pm 4.4 \%$ and $54.5 \pm 4.9 \%$ for $12 \mathrm{~L}$ and $16 \mathrm{~L}$, which indicated a significant increase $(p=0.012)$. The removed $\alpha_{1}$-MG quantity was $238.1 \pm 43.8 \mathrm{mg}$ and $254.9 \pm 52.6 \mathrm{mg}$ for $12 \mathrm{~L}$ and $16 \mathrm{~L}$, which indicated a significant increase $(p=0.036)$. The albumin leakage was $8.2 \pm 1.4 \mathrm{~g}$ and 9.7 $\pm 2.2 \mathrm{~g}$ for $12 \mathrm{~L}$ and $16 \mathrm{~L}$, which indicated a significant increase $(p=0.048)$. The SRIA was $29.1 \pm 3.1$ and $26.5 \pm$ 2.6 for $12 \mathrm{~L}$ and $16 \mathrm{~L}$.

In the predilution method, the RR of $\alpha_{1}$-MG was 45.3 $\pm 6.1 \%$ and $46.7 \pm 5.2 \%$ for $60 \mathrm{~L}$ and $84 \mathrm{~L}$. The removed $\alpha_{1}$-MG quantity was $224 \pm 77.1 \mathrm{mg}$ and $231.5 \pm 62.4 \mathrm{mg}$

Table 5 Albumin leakage and filtration capacity

\begin{tabular}{|c|c|c|c|c|c|c|c|}
\hline \multirow{2}{*}{$\begin{array}{l}\text { Substitution } \\
\text { volume } \\
\text { (L/session) }\end{array}$} & \multicolumn{3}{|l|}{ Predilution } & \multicolumn{3}{|l|}{ Postdilution } & \multirow[t]{2}{*}{$p$ (4 groups) } \\
\hline & 60 & $84(72)$ & $p$ & $12(10)$ & $16(12)$ & $p$ & \\
\hline \multicolumn{8}{|c|}{ Albumin leakage(g/ session) } \\
\hline TDF-20PV & $3.2 \pm 0.4$ & $5.3 \pm 0.8^{*}$ & 0.002 & $3.5 \pm 0.3$ & $4.7 \pm 0.7^{*}$ & 0.007 & $60-84 \mathrm{~L}, 60-16 \mathrm{~L}, 84-12 \mathrm{~L}, 12-16 \mathrm{~L}$ \\
\hline GDF-21 & $11.5 \pm 4.3$ & $11.5 \pm 5.9$ & 0.996 & $7.9 \pm 4.5$ & $16.5 \pm 8.8^{*}$ & 0.028 & 0.149 \\
\hline MFX-25U eco & $4.3 \pm 0.6$ & $5.6 \pm 1.3$ & 0.074 & $8.1 \pm 1.9$ & $13.2 \pm 3.9^{*}$ & 0.008 & $60-12 \mathrm{~L}, 60-16 \mathrm{~L}, 84-16 \mathrm{~L}, 12-16 \mathrm{~L}$ \\
\hline FIX-250S eco & $4.1 \pm 0.4$ & $3.7 \pm 0.5$ & 0.163 & $6.4 \pm 1.5$ & $6.6 \pm 1.8$ & 0.736 & $60-12 \mathrm{~L}, 60-16 \mathrm{~L}, 84-12 \mathrm{~L}, 84-16 \mathrm{~L}$ \\
\hline FIX-250U eco & $6.2 \pm 2.1$ & $6.7 \pm 1.7$ & 0.129 & $8.2 \pm 1.4$ & $9.7 \pm 2.2^{*}$ & 0.048 & $60-16 L$ \\
\hline \multicolumn{8}{|l|}{ SRIA } \\
\hline TDF-20PV & $42.7 \pm 10.9$ & $31.1 \pm 7.4^{*}$ & 0.005 & $41.1 \pm 7.6$ & $34.1 \pm 7.9^{*}$ & 0.01 & 0.089 \\
\hline GDF-21 & $22 \pm 8.2$ & $21.7 \pm 10.7$ & 0.936 & $33.7 \pm 16.3$ & $18.2 \pm 6.9$ & 0.072 & 0.118 \\
\hline MFX-25U eco & $38 \pm 7.3$ & $34.3 \pm 9.3$ & 0.286 & $28.3 \pm 10.7$ & $20.1 \pm 8^{*}$ & 0.005 & $60-16 \mathrm{~L}$ \\
\hline FIX-250S eco & $31.8 \pm 7.1$ & $34 \pm 9.1$ & 0.087 & $25.3 \pm 6.6$ & $24 \pm 5.7$ & 0.557 & 0.069 \\
\hline FIX-250U eco & $36.4 \pm 3.9$ & $34.4 \pm 3$ & 0.053 & $29.1 \pm 3.1$ & $26.5 \pm 2.6$ & 0.051 & $60-12 \mathrm{~L}, 60-16 \mathrm{~L}, 84-12 \mathrm{~L}, 84-16 \mathrm{~L}$ \\
\hline
\end{tabular}

Comparisons between $60 \mathrm{~L}$ and $84 \mathrm{~L}(72 \mathrm{~L})$ in the predilution and between $12 \mathrm{~L}(10 \mathrm{~L})$ and $16 \mathrm{~L}(12 \mathrm{~L})$ in the postdilution were analyzed by the corresponding $t$ test. ${ }^{*} P<0.05$. And comparison among four treatment conditions for each membrane was analyzed by one-way ANOVA and Tukey-Kramer test 
for $60 \mathrm{~L}$ and $84 \mathrm{~L}$. The albumin leakage was $6.2 \pm 2.1 \mathrm{~g}$ and $6.7 \pm 1.7 \mathrm{~g}$ for $60 \mathrm{~L}$ and $84 \mathrm{~L}$. The SRIA was $36.4 \pm$ 3.9 and $34.4 \pm 3$ for $60 \mathrm{~L}$ and $84 \mathrm{~L}$ (Tables 4 and 5).

\section{Relationship between the removed $a_{1}-M G$ quantity and the albumin leakage quantity}

In the TDF group and GDF group, we saw no correlation between the removed $\alpha_{1}$-MG quantity and albumin leakage quantity (Fig. 1a, b).

We observed a positive correlation of the removed $\alpha_{1}$-MG quantity to the albumin leakage quantity in the MFX group (Spearman's $r=0.576, p=0.006$ ), FIX-S group (Spearman's $r=0.552, p=0.008$ ), and FIX-U group (Spearman's $r=0.829, \quad p=0.0001$ ) (Fig. 1c-e).

The correlation coefficient tended to differ according to the membrane, and in particular, the FIX-U group showed a strongly positive correlation between the removed $\alpha_{1}$-MG quantity and the albumin leakage quantity (Fig. 1e).

\section{Change over time in TMP}

In the TDF group, the TMP lowered the postdilution method and predilution method for $60 \mathrm{~L}$. Although the TMP showed a high value of $268 \pm 72 \mathrm{mmHg}$ in the predilution method for $84 \mathrm{~L}$ at $240 \mathrm{~min}$, the albumin leakage quantity was $5.3 \pm 0.8 \mathrm{~g}$, so we observed no excessive albumin leakage quantity (Fig. 2a).

In the GDF group, the TMP was high in both the postdilution and predilution HDF. In the postdilution method, the TMP was showed $122 \pm 140 \mathrm{mmHg}$ for $12 \mathrm{~L}$ at $240 \mathrm{~min}$, but the albumin leakage quantity increased excessively to $16.5 \pm 8.8 \mathrm{~g}$. On the other hand predilution method, the TMP was showed $166 \pm 148 \mathrm{mmHg}$ and $237 \pm 181 \mathrm{mmHg}$ for $60 \mathrm{~L}$ and $72 \mathrm{~L}$ at $240 \mathrm{~min}$, and the albumin leakage quantity was approximately $11.5 \mathrm{~g}$, which was nearly the same between them (Fig. 2b).

The TMP in the MFX group, FIX-S group, and FIX-U group was lowered for both postdilution and predilution approaches. However, the albumin leakage quantity varied depending on the membrane, and postdilution by 12 $\mathrm{L}$ showed $13.2 \pm 3.9 \mathrm{~g}$ in the MFX group, $6.6 \pm 1.8 \mathrm{~g}$ in

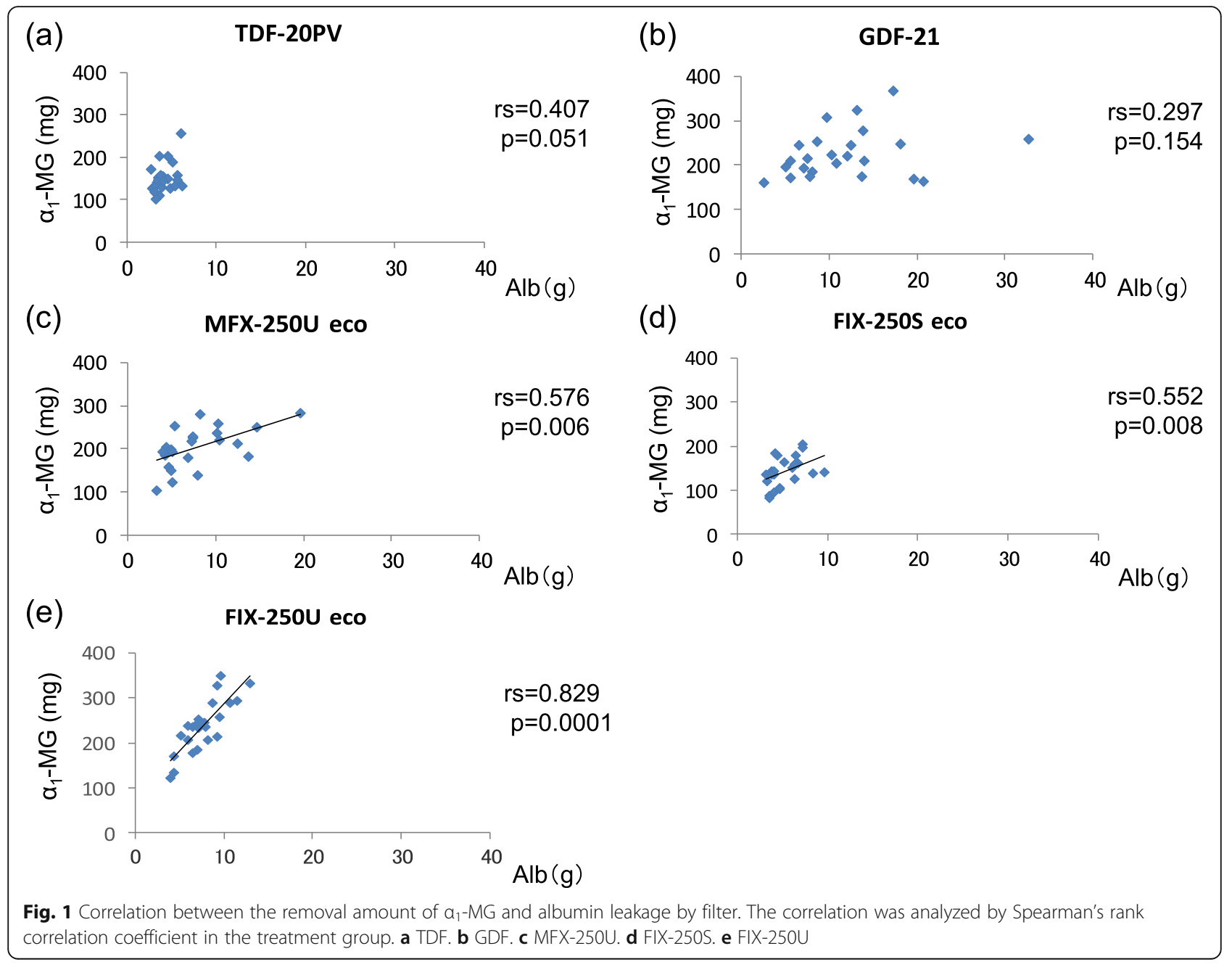




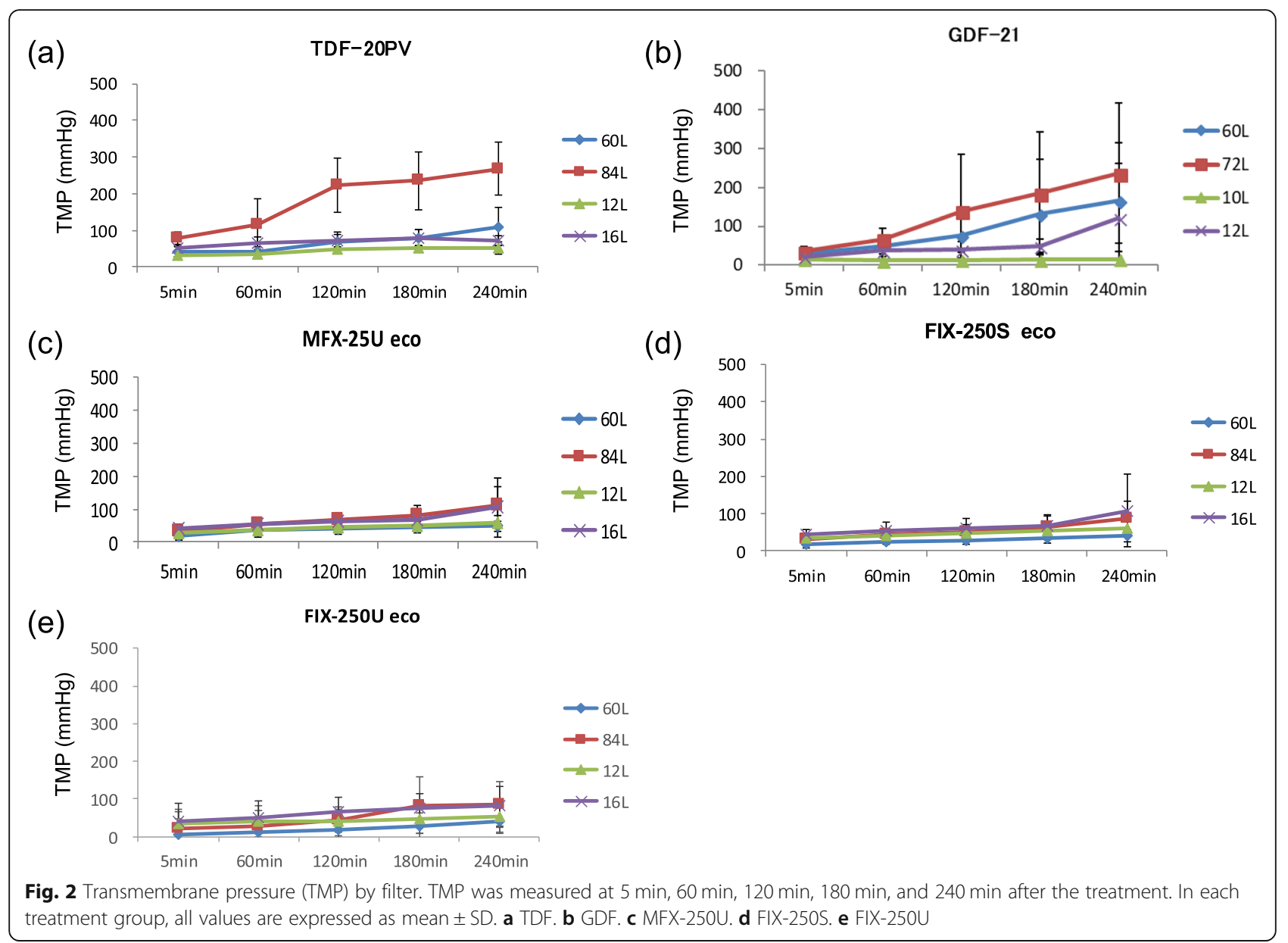

the FIX-S group, and $9.7 \pm 2.2 \mathrm{~g}$ in the FIX-U group (Fig. 2c-e).

\section{Discussion}

High-volume postdilution OL-HDF has become one of the mainstreams in chronic dialysis based on the evidence of randomized control trials conducted mainly in Europe [1-3]; however, the membrane performances or solute removal properties have never discussed in these trials. In other words, it has not been clear on how they should increase the substitution volume or how they modified the dialysis prescriptions. The mechanism of the better survival in the high-volume HDF group has also still been unclear. On the other hand, in Japan, the dialysis prescriptions are determined according to solute removal, which includes albumin leakage quantity and the RRs and removed amounts of $\alpha_{1}$-MG and $\beta_{2}$-MG. To achieve the target of the removal of them, we increase the substitution volume. OL-HDF was originally developed to effectively remove the middle molecules, and so we need the removal targets for them. The molecular weights of the middle molecules range from 1000 to $50,000 \mathrm{Da}$, and there are also many other functional proteins like inflammatory cytokines $[7,8]$. Although it has been reported that low serum $\beta_{2}$-MG concentration decreased the risk of dialysis-related amyloidosis and mortality risk [9-11], in Japan, there is also a focus on the removal of larger LMWPs as $\alpha_{1}$-MG and albumin, in addition to $\beta_{2}$-MG $[12,13]$. The molecular weight of $\alpha_{1}$-MG is $33,000 \mathrm{Da}$, and while this compound has not been recognized as a uremic toxin but a uremic retention solute. However, there have been reports on the link between $\alpha_{1}$-MG removal and improvement of clinical symptoms like joint pain, pruritus, and restless leg syndrome (RLS), with an $\alpha_{1}$-MG removal rate of at least $38 \%$ required to improve the symptoms of intractable RLS, which is a problem observed in long-term dialysis patients [14, 15]. Interleukin-6 (IL-6) and prolactin are uremic toxins with a similar molecular weight of $\alpha_{1}$-MG. IL-6 is one of the inflammatory cytokines that regulate humoral immunity, with a molecular weight of 21,000 to $28,000 \mathrm{Da}$. For this reason, the removal rate of $\alpha_{1}$-MG has been usually used for evaluating the removal of LMWPs and it indicates the recent trend of OL-HDF 
in Japan for the proactive removal of LMWPs larger than $\beta_{2}$-MG.

However, if we try to increase the removal of $\alpha_{1}-\mathrm{MG}$, some albumin leakage during a dialysis session is unpreventable because the Stokes radius of $\alpha_{1}-\mathrm{MG}$ is similar to that of albumin at $28.4 \AA$ and $35.5 \AA$, respectively, regardless of the difference of the molecular weight as $33,000 \mathrm{Da}$ and $66,000 \mathrm{Da}[16,17]$. Thus, SRIA was established for assessing the selectivity of the $\alpha_{1}$-MG removal to avoid excessive albumin leakage. However, if the amount of albumin leakage is small, even with a lower amount of $\alpha_{1}$-MG removed, it would provide a high calculated SRIA; while on the other hand, excessive albumin leakage would decrease SRIA. For this reason, it is important to evaluate the correlation between the removed amount of $\alpha_{1}$-MG and the albumin leakage quantity, as well as the $\alpha_{1}$-MG removal rate altogether.

The results in the current study also suggest that it is better to choose postdilution for the proactive removal of LMWPs that excels in solute removal and also to increase the substitution volume. The removal properties of $\beta_{2}$-MG were not different depending on the membrane used, the dilution method, or the substitution volume, so we could consider that $\beta_{2}$-MG was removed not only by the diffusion, but also by the convection. However, the RR of $\alpha_{1}$-MG in the MFX and FIX-U groups was better in high-volume postdilution methods than predilution methods. On the other hand, like GDF, we also identified a membrane where the albumin leaks excessively when following a postdilution approach and increasing the substitution volume. The high-volume postdilution could have a risk of excessive albumin leakage depending on the membrane, so we should consider the safety of the treatment. With synthetic polymer membranes except ATA showing the albumin leakage quantity increased and the SRIA decreased particularly in postdilution, the correlation coefficient between the $\alpha_{1}$-MG removal quantity and the albumin leakage was between 0.3 and around 0.6. It suggests that the removal of $\alpha_{1}$-MG would become a plateau as the albumin leakage increases in the current synthetic polymer membranes. From this viewpoint, the high-volume postdilution HDF is not a good modality to selectively and safely remove $\alpha_{1}$-MG and the similar LMWPs because it particularly increases the albumin leakage.

The driving force of solute removal in convection therapies is TMP, and the influence of TMP on albumin leakage differed depending on the membrane being used. When we increase the substitution volume, we should evaluate the TMP, the removal property of LMWPs, and the albumin leakage for the safety of the therapy. Increase of TMP during a dialysis session means the formation of protein fouling on the membrane surface, and it is different depending on the membrane being used. The protein fouling is one of the important triggers of explosive albumin leakage and may deteriorate the solute removal itself. However, there was an explosive albumin leakage of $16.5 \pm 8.8 \mathrm{~g}$ in the postdilution HDF with the substitution volume of $12 \mathrm{~L}$ in the GDF group even without an increase in TMP. It suggests that a wrong dialysis choice in the high-volume postdilution HDF occasionally might not be safe for the patients. We would like to propose measuring the removed amount of LMWPs and the albumin leakage in the spent dialysate for the evaluation of the efficacies and safety of the therapy.

ATA is a newly developed membrane to provide high convective therapy, and it has a smooth inner surface to avoid the formation of protein fouling and the increase of TMP during a dialysis session. In the current study, ATA membrane (FIX series) can be used safely for both the postdilution OL-HDF as well as the predilution OL-HDF. The albumin leakage remains unchanged in both postdilution and predilution methods when the substitution volume was increased. In the predilution HDF with the FIX series, we can increase the substitution volume while keeping the albumin leakage at around $4 \mathrm{~g} / \mathrm{session}$. It might maintain the oncotic and plasma osmotic pressures, so we believe this method can be beneficial for patients with intradialytic hypotension [18]. In the postdilution HDF with FIX-S, the albumin leakage stayed constant at $6.6 \pm 1.8 \mathrm{~g} / \mathrm{session}$, even when the substitution volume was raised up to $16 \mathrm{~L}$. However, the removal rate of $\alpha_{1}$-MG was not enough even when increasing the substitution volume while suppressing excessive albumin leakage. The RR of $\alpha_{1}$-MG by FIX-S is $27.1 \pm 7.4 \%$ for $84 \mathrm{~L}$ by predilution and $34.6 \pm 6.5 \%$ for $16 \mathrm{~L}$ by postdilution. There were no significant differences in the $\alpha_{1}$-MG removal for both predilution and postdilution, so the superiority of high-volume postdilution is not recognized. The FIX-U series has a larger pore size of the membrane than the FIX-S series. The removal rate of $\alpha_{1}$-MG by FIX-U was $46.7 \pm 5.2 \%$ for $84 \mathrm{~L}$ by predilution and $54.5 \pm 4.9 \%$ for $16 \mathrm{~L}$ by postdilution. Furthermore, the correlation coefficient between $\alpha_{1}$-MG removal quantity and albumin leakage quantity shows a strong positive correlation of 0.829 , which allowed us to confirm that $\alpha_{1}$-MG removal is increasing relative to albumin leakage. Therefore, FIX-U can safely increase the substitution volume while suppressing the excessive albumin leakage, which would therefore be an excellent choice for the selective removal of $\alpha_{1}$-MG even with the high-volume postdilution. As previously addressed, the high-volume postdilution OL-HDF with the current synthetic polymer membranes could have a risk of excessive albumin leakage. The FIX series should be a good choice to avoid this phenomenon. In Japan, the average blood flow rate has been lower 
than that in Europe, so we could not increase the substitution volume in postdilution HDF for the fear of the excessive albumin leakage. However, FIX-U can be considered a great option for selective and sufficient removal of $\alpha_{1}-\mathrm{MG}$ in the postdilution HDF as well as the predilution HDF.

In the current study, we did not evaluate the relationship between the removal of LMWPs or SRIA and the patient survival. Recently, the survival advantages of Japanese-style predilution OL-HDF with the substitution volume greater than $40 \mathrm{~L}$ predilution were reported but the removal of LMWPs was not determined in the study [19]. In the future, there is an urgent need to elucidate the relationship between the LMWPs' removal and the patient's survival.

\section{Conclusions}

The removal of LMWPs varies dramatically depending on the dialysis prescription, such as the choice of the membrane, the dilution method, and the substitution volume as presented in the current study. Although high-volume postdilution OL-HDF has been widely provided in the world, it has a risk of excessive albumin leakage during dialysis session in certain prescriptions. To improve the safety and dialysis-related symptoms, it is necessary to choose a proper dialysis prescription for each patient by evaluating the removal properties of larger LMWPs such as $\alpha_{1}$-MG and albumin leakage quantity. The newly launched ATA membrane could remove $\alpha 1-\mathrm{MG}$, selectively suppressing the excessive albumin leakage and increasing the substitution volume safely both in the high-volume postdilution and the predilution OL-HDF.

\section{Abbreviations \\ Alb: Albumin; ATA: Asymmetric triacetate; CTA: Cellulose triacetate; DW: Dry weight; HD dur: Hemodialysis duration; HD: Hemodialysis; HDF: Hemodiafiltration; HGB: Hemoglobin; Ht: Hematocrit; IL: Interleukin; LMWPs: Low molecular weight proteins; MW: Molecular weight; PEPA: Polyester polymer alloy; PES: Polyethersulfone; PLT: Platelet; PS: Polysulfone; QB: Quantity of blood flow; QD: Quantity of dialysate flow; QS: Quantity replacement fluid; RA: Removal amount; RBC: Red blood cell count; RLS: Restless leg syndrome; RR: Removal rate; SC: Sieving coefficient; SRIA: Selective removal index of $a_{1}$-microglobulin; TMP: Transmembrane pressure; TP: Total protein; UFR: Ultrafiltration coefficient; WBC: White blood cell count; $\mathrm{a}_{1}$-MG: $\mathrm{a}_{1}$-microglobulin}

\section{Acknowledgements}

We thank Dr. Ikuto Masakane for the excellent academic assistance.

\section{Funding}

There is no funding for the current study.

\section{Availability of data and materials}

1. When anyone wants to use the data and materials from the current manuscript without modifications, all data and materials are freely available.

2. All data generated or analyzed during this study are included in this published article.
Authors' contributions

YT designed the study, performed the data analysis, and wrote the manuscript. YT, HA, DH, and HM collected the clinical data. All authors read and approved the final manuscript.

\section{Ethics approval and consent to participate}

1. This research was approved by the ethical committee of Kawashima Hospital. The approval no. is 0199.

2. The original data had been totally anonymized, so there are no risks for deteriorating the privacy of patients.

3. The data presented in the current manuscript does not contain any images, videos, and voice recording which might have a risk for identifying an individual.

Consent for publication

Not applicable.

\section{Competing interests}

The authors declare that they have no competing interests.

\section{Publisher's Note}

Springer Nature remains neutral with regard to jurisdictional claims in published maps and institutional affiliations.

\section{Author details}

${ }^{1}$ Clinical Engineering Department, Social Medicine Corporation Kawashima Association, Kawashima Hospital, 1-1-39, Kitasako, Tokushima City, Tokushima Prefecture 770-0011, Japan. ${ }^{2}$ Kidney Internal Medicine (Dialysis, Renal Transplantation), Tokushima, Japan.

Received: 29 January 2019 Accepted: 11 April 2019

Published online: 21 May 2019

\section{References}

1. Grooteman MP, van den Dorpel MA, Bots ML, et al. CONTRAST Investigators Effect of online hemodiafiltration on all-cause mortality and cardiovascular outcomes. J Am Soc Nephrol 2012; 23: 1087-1096.

2. Maduell F, Moreso F, Pons M, et al. ESHOL Study Group High-efficiency postdilution online hemodiafiltration reduces all-cause mortality in hemodialysis patients. J Am Soc Nephrol 2013; 24: 487-497.

3. Ok E, Asci G, Toz H, et al. Turkish Online Haemodiafiltration Study Mortality and cardiovascular events in online haemodiafiltration (OL-HDF) compared with high-flux dialysis: results from the Turkish OL-HDF Study. Nephrol Dial Transplant 2013: 28: 192-202.

4. Masakane I, Taniguchi S, Nakai S, et al. Annual dialysis data report 2016, JSDT renal data registry. Ren Replace Ther. 2018;4:45. https://doi.org/10. 1186/s41100-018-0183-6.

5. Masakane I, Sakurai K. Current approaches to middle molecule removal: room for innovation. Nephrol Dial Transplant. 2018;33:iii12-21.

6. Saito A, Ogawa H, Takagi T, et al. Long-term clinical evaluation of proteinpermeating hemodiafiltration. Artif Organ. 1984;13:643-6 (in Japanese).

7. Vanholder R, Smet RD, Glorieux $\mathrm{G}$, et al. Review on uremic toxins: classification, concentration, and interindividual variability. Kidney Int. 2003;63:1934-43.

8. Duranton F, Cohen G, De Smet R, et al. Normal and pathologic concentrations of uremic toxins. J Am Soc Nephrol. 2012;23:1258-70.

9. Okuno $\mathrm{S}$, Ishimura $\mathrm{E}$, Kohno $\mathrm{K}$, et al. Serum beta2-microglobulin level is a significant predictor of mortality in maintenance haemodialysis patients. Nephrol Dial Transplant. 2009;24:571-7.

10. Hoshino J, Yamagata K. Significance of the decreased risk of dialysis-related amyloidosis now proven by results from Japanese nationwide surveys in 1998 and 2010. Nephrol Dial Transplant. 2016;31:595-602.

11. Cheung AK, Rocco MV, Yan G, et al. Serum beta2-microglobulin levels predict mortality in dialysis patients: results of the HEMO study. J Am Soc Nephrol. 2006;17:546-55.

12. Tsuchida K, Nagai K, Minakuchi J, et al. Evidence for targeting lowmolecular-weight proteins in hemodialysis and hemodiafiltration. Scientific Aspect of Dialysis Therapy: JSDT/ISBP Anniversary Edition. Contrib Nephrol. 2017;189:189-96. 
13. Nagai K, Tsuchida K, Minakuchi J, et al. Implications of albumin leakage for survival in maintenance hemodialysis patients: a 7-year observational study. Ther Apher Dial. 2017;21:378-86.

14. Sakurai K. Biomarkers for evaluation of clinical outcomes hemodiafiltration. Blood Purif. 2013;35:64-8.

15. Yamashita AC, Sakurai K. Clinical effect of pre-dilution hemodiafiltration based on the permeation of the hemodiafilter. Contrib Nephrol. 2015;185:17. https://doi.org/10.1159/000380964 Epub 2015 May 19.

16. Inge A. Characterization of proteins and other macromolecules by agarose gel chromatography. J Chromatogr A. 1987;152(1):21-32. https://doi.org/10. 1016/50021-9673(00)85330-3

17. Lena $W$, Jonas F, Tord $L$, et al. Carbohydrate groups of a1microglobulin are important for secretion and tissue localization but not for immunological properties. Glycobiology. 2000;10(9):891-900. https://doi.org/10.1093/glycob/10.9.891.

18. Tsuchida K. Knowledge of the correct on-line hemodiafiltration. J J.pn Soc Dial Ther. 2014;47:663-70 (in Japanese).

19. Kikuchi K, Hamano T, Wada A, Nakai S, Masakane I. Predilution on-line hemodiafiltration is associated with improved survival compared to hemodialysis. Kidney Int. 2019; (in press).

Ready to submit your research? Choose BMC and benefit from:

- fast, convenient online submission

- thorough peer review by experienced researchers in your field

- rapid publication on acceptance

- support for research data, including large and complex data types

- gold Open Access which fosters wider collaboration and increased citations

- maximum visibility for your research: over $100 \mathrm{M}$ website views per year

At $\mathrm{BMC}$, research is always in progress.

Learn more biomedcentral.com/submissions 